\title{
Inhibition of Heat Shock Protein 90 with AUY922 Represses Tumor Growth in a Transgenic Mouse Model of Islet Cell Neoplasms
}

\author{
Volker Fendrich ${ }^{a}$ Sven Wichmann ${ }^{a}$ Dominik Wiese ${ }^{a}$ Jens Waldmann ${ }^{a}$ \\ Matthias Lauth ${ }^{b}$ Peter Rexin ${ }^{c}$ Carolin L.-Lopez ${ }^{a}$ Hans J. Schlitt ${ }^{d}$ \\ Detlef K. Bartscha Sven A. Lang ${ }^{d}$ \\ ${ }^{a}$ Department of Surgery, Philipps University Marburg, ${ }^{b}$ Institute of Molecular Biology and Tumor Research, and \\ ${ }^{c}$ Department of Pathology, University of Marburg, Marburg, and ${ }^{d}$ Department of Surgery, University Hospital \\ Regensburg, University of Regensburg, Regensburg, Germany
}

\section{Key Words}

Heat shock protein $90 \cdot$ AUY922 - Transgenic RIP1-Tag2

mice $\cdot$ Islet cell tumors

\begin{abstract}
Background: This study was designed to evaluate the role of heat shock protein 90 (HSP90) in tumor progression of murine islet cell tumors. Blockade of HSP90 has recently been proposed as a therapeutic target, but effects in models of islet cell tumors with AUY922, a newly developed HSP90 inhibitor, have not been examined. Material and Methods: The carcinoid cell line BON-1 and the HSP90 inhibitor AUY922 were used to determine effects on signaling and growth in vitro. In vivo transgenic RIP1-Tag2 mice, which develop islet cell neoplasms, were treated with vehicle or AUY922 $(25 \mathrm{mg} /$ $\mathrm{kg} / \mathrm{twice}$ per week) from week 5 until death. The resected pancreata were evaluated macroscopically and microscopically by immunohistochemistry. Quantitative real-time PCR was performed for HSP90 targets with RNA from islets isolated from treated and untreated RIP1-Tag2 mice. Results: HSP90 blockade impaired constitutive and growth factorinduced signaling in vitro. Moreover, HSP90 inhibition attenuated in vitro cell growth in a dose-dependent manner. In vivo, AUY922 significantly reduced tumor volume by $92 \%$
\end{abstract}

compared to untreated controls $(p=0.000)$, and median survival in the used transgenic mouse model was prolonged (110 vs. 119 days; $p=0.75$ ). Quantitative real-time PCR for downstream target genes of HSP90 demonstrated significant downregulation in the islet cell tumors of RIP1-Tag2 mice treated with AUY922, confirming our ability to achieve effective pharmacologic levels of AUY922 within the desired tissue site in vivo. Conclusion: This is the first study to show that the HSP90 antagonist AUY922 may provide a new option for therapy of islet cell neoplasms.

ㄷ) 2014 S. Karger AG, Basel

\section{Introduction}

Pancreatic neuroendocrine neoplasia ( $\mathrm{pNEN}$ ) represents a rare, but important subset of pancreatic neoplasms. These tumors account for $2-4 \%$ of all clinically detected pancreatic tumors. Their overall incidence is approximately 1 in 100,000 people per year [1]. pNENs present as either functional tumors, causing specific hormonal syndromes like Zollinger-Ellison syndrome or or-

V.F. and S.W. contributed equally to this work.

\section{KARGER}

E-Mail karger@karger.com

www.karger.com/nen (c) 2014 S. Karger AG, Basel

0028-3835/14/1004-0300\$39.50/0
Volker Fendrich, MD

Department of Surgery, Philipps University Marburg

Baldingerstrasse

DE-35043 Marburg (Germany)

E-Mail fendrich@med.uni-marburg.de 
ganic hyperinsulinism, or as nonfunctional pNENs (NFpNENs) [1-3]. The natural history of pNENs is highly variable. Small, benign neoplasms such as $90 \%$ of all sporadic insulinomas are readily curable by surgical resection. Most other functional and all NF-pNENs have a less favorable prognosis. Survival is determined usually by the natural history of the neoplasm, its local aggressiveness and the development of distant metastases. Metastases usually occur first in the liver and are amenable to treatment by several invasive techniques [1-3]. The major effect of established biotherapy with interferon and somatostatin analogues is tumor growth stabilization rather than inducing regression [4].

New molecular-targeted therapies that exploit some of the well-known biological properties of pNENs, such as presence of somatostatin, peptide and tyrosine kinase receptors or high vascularity, are currently being evaluated in clinical trials [5]. Recently, Mayer et al. [6] found heat shock protein 90 (HSP90) to be expressed in $95 \%$ of specimens from pNEN patients. HSP90 is a molecular chaperone that comprises $1-2 \%$ of total cellular protein content and regulates the correct folding, activity, function, and stability of over 200 client proteins [7]. Under the circumstances of enhanced stress on the cell, the amount of intracellular HSP90 is augmented to levels of $4 \%$ or more of the total protein concentration [8].

Among the HSP90 client proteins, growth factor receptors [e.g. insulin-like growth factor-I receptor (IGFIR), epidermal growth factor receptor (EGFR) or cMET], intracellular signaling intermediates (e.g. Akt, ERK, BRAF) and transcription factors (e.g. HIF-1a, c-Myc) have been implicated in tumor growth and metastasis in pNENs [9-12]. We and others have previously shown that treatment with HSP90 blockers impairs activation and expression of these client proteins in various cancer models [13-15]. Recently, synthetic inhibitors of HSP90 belonging to the family of isoxazole derivatives have entered clinical phase trials [16, 17]. Among them, AUY922 is one of the most potent isoxazole-based small-molecule inhibitors of HSP90 that has already shown antineoplastic activity in some tumor models $[15,17]$. Therefore, targeting HSP90 with AUY922 might also be a promising approach for therapy of pNENs.

The RIP1-Tag2 mouse model of pancreatic islet carcinoma represents a model of spontaneous multistep tumorigenesis. Transgenic mice express the oncogene SV40 T antigen (Tag) under the control of the rat insulin gene promoter (RIP) and display distinct stages of tumor progression: onset of hyperproliferation, induction of angiogenesis and formation of solid tumors [18]. Among RIP-Tag transgenic lines, RIP1-Tag2 mice express the oncogene during embryonic development and succumb to insulinomas by the age of 14 weeks. Tumor development in these mice proceeds through a series of discrete stages, in which approximately $50 \%$ of the 400 islets in the pancreas become hyperproliferative, of which a subset subsequently acquires the ability to switch on angiogenesis. A subset of these angiogenic islets develops into tumors, both benign, encapsulated lesions and invasive carcinomas [19]. Therefore, this model provides a unique opportunity to study the effect of new drug therapies in a preclinical setting [20].

In the present study, we show that pharmacological HSP90 blockage with AUY922 impairs activation of oncogenic signaling in vitro and reduces tumor growth, and prolongs survival in the RIP1-Tag2 model. In summary, these results provide a solid basis for the use of HSP90 inhibitors in clinical strategies for therapy of pNEN.

\section{Material and Methods}

Mice

The generation of RIP1-Tag2 mice as a model of pancreatic islet cell carcinogenesis has been previously reported [18]. The mice used in this study were males and females of the RIP1-Tag2 transgenic mouse lineage inbred in the $\mathrm{C} 57 \mathrm{Bl} / 6 \mathrm{~J}$ background. All experiments had been approved by the local Committees for Animal Care and Use. All animals were maintained in a climate-controlled room kept at $22^{\circ} \mathrm{C}$, exposed to a 12:12-hour light-dark cycle, fed standard laboratory chow, and given water ad libitum.

\section{Genotyping}

For genotyping, genomic DNA was extracted from tail cuttings using the REDExtract-N-Amp ${ }^{\mathrm{TM}}$ Tissue PCR kit (Sigma-Aldrich, Saint Louis, Mo., USA). A PCR reaction was carried out for each animal to test for the presence of Tag2. Primer sequences used were: TAG1 - 5'-GGA CAA ACC ACA ACT AGA ATG CAG-3' and TAG2 - 5' ${ }^{\prime}$-CAG AGC AGA ATT GTG GAG TGG-3'.

\section{HSP90 Inhibitor AUY922}

AUY922 was kindly provided by Novartis Oncology (Basel, Switzerland). The chemical structure of AUY922 is shown in figure 1. According to Novartis, the oral bioavailability of AUY922 is very low in rodents despite a high intrinsic absorption. This is likely due to a high first pass metabolism and rapid clearance. Since the oral bioavailability of AUY922 is low, the preferred route of administration is i.p.

\section{Drug Treatment}

RIP1-Tag2 transgenic mice were randomly assigned to receive either (a) mock treatment $(n=29)$ or (b) AUY922 ( $n=29)$. Twenty animals of each group were treated from week 5 until week 12. Nine mice from each group were treated from week 5 until death or severe signs of hypoglycemia. For in vivo dosing in mouse tumor models, doses between 25 and $50 \mathrm{mg} / \mathrm{kg} /$ twice per week i.p. have been recommended $[15,17,21]$. For the present study, a dos- 


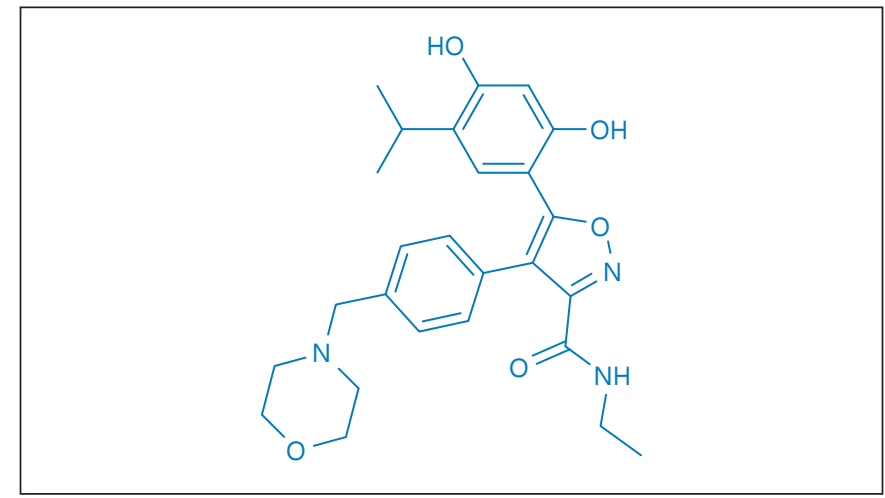

Fig. 1. Molecular structure of AUY922.

age of $25 \mathrm{mg} / \mathrm{kg} /$ twice a week i.p. was chosen. This dosage was suggested by Novartis as being that equivalent to a dosage given to patients. For mock treatment, a vehicle solution for AUY 922 was given. In cases where littermates were available for drug treatment, only the first mouse was randomly assigned to one of the two given treatment groups; the second littermate was then assigned to the 'matched' control arm. This scheme was chosen in order to obtain the highest possible degree of consistency and to avoid randomization bias as far as possible.

\section{Preparation of AUY922}

As vehicle, a solution of $5 \%$ glucose was prepared. The calculated amount of AUY 922 powder was added to the vehicle and left in a glass container overnight at $4^{\circ} \mathrm{C}$. The following morning, the suspension was mixed and sonicated using the Misonix Sonicator 3000 (Sonicator, Newton, Conn., USA) for 2-3 min. This procedure was repeated until a fine suspension with particles that are not visible anymore was obtained.

\section{Necropsy and Assessment of Islet Cell Tumor Growth}

The animals were weighed twice weekly and monitored daily for signs of distress and cachexia, and were euthanized if they became moribund or when they showed severe signs of hypoglycemia.

The pancreas was removed, weighted and inspected for grossly visible tumors and either preserved in $4 \%$ formalin solution (Sigma-Aldrich, Hamburg, Germany) for histology or processed for RNA extraction (see below). For evaluating a change in islet cell neoplasm growth, four sections from each mouse were analyzed as described previously [20]. These sections were taken 1, 10,20, and $40 \mu \mathrm{m}$ from the surface of the pancreas and HE stained. All the islets were marked, and their surface measured with the Leica QWin image analysis (Leica, Wetzlar, Germany; fig. 2). Results are given in $\mu \mathrm{m}^{2}$. After measuring all islets, the total surface of all islets from each group was added and compared.

\section{Immunostaining}

For immunolabeling, formalin-fixed and paraffin-embedded archived tumor samples and corresponding normal tissues were stained as previously described [22]. Concentrations and sources of primary antibodies are available on request. Briefly, slides were heated to $60^{\circ} \mathrm{C}$ for $1 \mathrm{~h}$, deparaffinized using xylene, and hydrated by a graded series of ethanol washes. Antigen retrieval was accom- plished by microwave heating in $10 \mathrm{~mm}$ sodium citrate buffer of pH 6.0 for 10 min. For immunohistochemistry, endogenous peroxidase activity was quenched by 10 -min incubation in $3 \% \mathrm{H}_{2} \mathrm{O}_{2}$. Nonspecific binding was blocked with $10 \%$ fetal bovine serum. Sections were then probed with primary antibodies overnight at $4^{\circ} \mathrm{C}$. For immunohistochemistry, bound antibodies were detected using the avidin-biotin complex peroxidase method (ABC Elite Kit, Vector Labs, Burlingame, Calif., USA). Final staining was developed with the Sigma FAST DAB peroxidase substrate kit (Sigma, Deisenhofen, Germany). The immunohistochemistry results were scored as described previously [20]: negative $=$ less than $5 \%$ cells positive; $+=<30 \%$ cells positive; $++=>30 \%$ cells positive. Ki67- and caspase-3-positive cells were counted by manual assessment within defined $10 \times$ fields of view ( $n=3$ /section; 3 sections analyzed/animal). Ki67- and caspase-3-positive cells were counted as a fraction of total nuclei within a region.

\section{Mouse Islet Isolation}

Isolation buffer was mixed by HBSS containing $10 \mathrm{mM}$ of HEPES, $1 \mathrm{mM}$ of $\mathrm{MgCl}_{2}$, and $5 \mathrm{mM}$ of glucose to a $\mathrm{pH}$ of 7.4. Collagenase P (Boehringer Mannheim-Roche, Ingelheim, Germany) was added to the isolation buffer and dissolved by vortexing. $2 \mathrm{ml}$ of collagenase solution was dispensed into each glass vial and placed on ice. Just before dissection, animals were sacrificed by cervical dislocation. After laparotomy, the bowel was removed to the left side of the open mouse to expose the pancreas and common bile duct. A hemostat clamp was placed on either side of the duodenum, where the bile duct drains, leaving a small pocket for collagenase solution to enter the intestine. The pancreas was inflated through the bile duct with a 30 -gauge needle and 5-ml syringe containing $3 \mathrm{ml}$ of cold collagenase solution, starting at the gall bladder. The pancreas was removed and placed in a siliconized vial containing $2 \mathrm{ml}$ of collagenase solution. The vial was placed into a $37^{\circ} \mathrm{C}$ water bath and incubated for $13 \mathrm{~min}$ and rigorously shaken afterwards. Each digest was poured through a large sterile sink strainer into a sterile $1,000-\mathrm{ml}$ beaker. The digests were placed into 50 - $\mathrm{ml}$ conical tubes and spun down at 1,300 rpm. The supernatant was aspirated and the pellet resuspended by tapping vigorously and adding $50 \mathrm{ml}$ of wash buffer. This step was repeated three times. Then, the pellet was resuspended in $7 \mathrm{ml}$ of Ficoll, and repeated for different Ficoll densities (1.108, 1.096, 1.069, and then 1.037). Islets were picked from the second layer using sterile plastic eye dropper. All collections were then transferred to a $50-\mathrm{ml}$ conical tube containing $\sim 25 \mathrm{ml}$ of cold buffer. Islets were resuspended in $20 \mathrm{ml}$ RPMI-1640 (containing 10\% FCS and penicillin and streptomycin, HEPES, MEM-NEAA) and mixed gently. Islets were then confirmed as islet cells by running real-time RT-PCR for endocrine (e.g. insulin) and exocrine (e.g. amylase) markers and were then stored at $-80^{\circ} \mathrm{C}$ for further processing.

\section{Cell Culture}

BON-1 pancreatic carcinoid cells [23] were grown in DMEM/ FK-12 (Invitrogen, Carlsbad, Calif., USA) supplemented with 10\% fetal calf serum (FCS; Invitrogen) and $1 \times$ Pen/Strep (Biofluids, Camarillo, Calif., USA) at $37^{\circ} \mathrm{C}$ in a humidified atmosphere containing $5 \% \mathrm{CO}_{2}$. The cell line was routinely tested for mycoplasma infection using the MycoSensor PCR Assay Kit (Stratagene, La Jolla, Calif., USA). Epidermal growth factor (EGF), hepatocytegrowth factor (HGF) and IGF-I were obtained from R\&D Systems (Minneapolis, Minn., USA). 

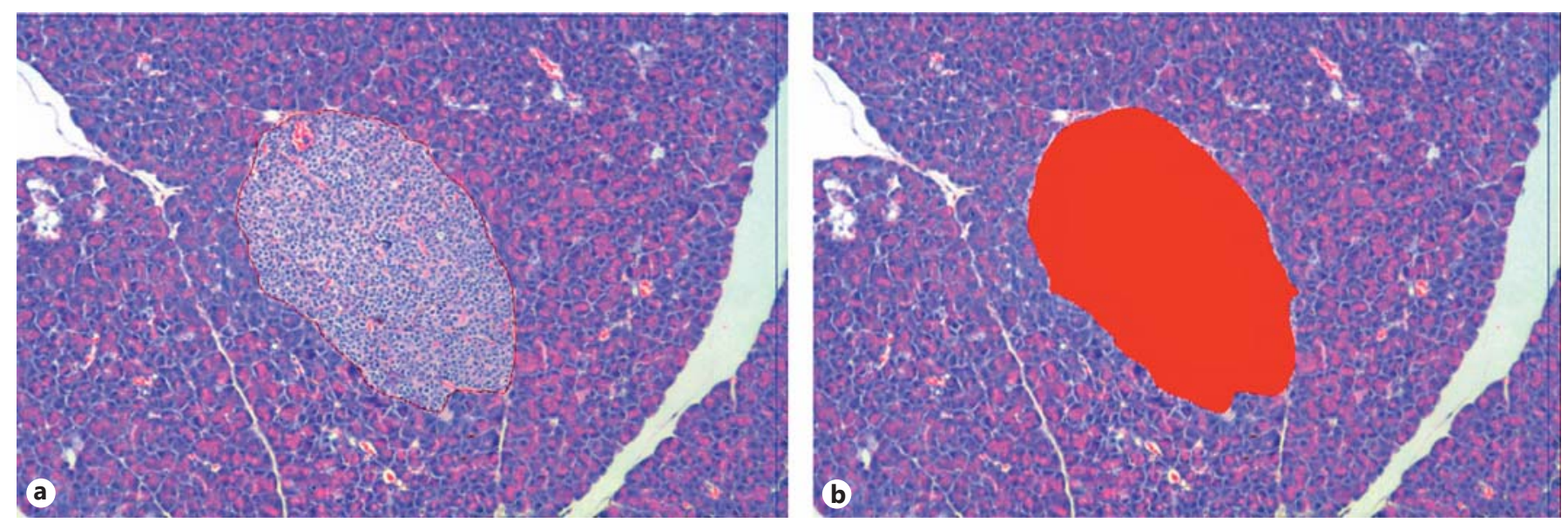

Fig. 2. All islets were marked and their surface measured with the Leica QWin image analysis (Leica).

Measurement of Tumor Cell Growth in vitro

To evaluate effects of HSP90 blockade with AUY922, tumor cells were seeded in 96-well plates $\left(1 \times 10^{3}\right.$ per well) for 24,48 and $72 \mathrm{~h}$ under full medium (10\% FCS). We used the MTT [3-(4,5-dimethylthiazol-2-yl)-2,5-diphenyltetrazolium, SigmaAldrich, Hamburg, Germany] assay to assess cell growth as described before [13].

\section{Western Blotting for HSP90 Clients}

Experiments were performed at a cell density of $60-70 \%$. Cells were incubated with AUY922 for 2 and $24 \mathrm{~h}$ under full medium conditions. Whole-cell lysates were prepared as described elsewhere [13]. Protein samples $(50 \mu \mathrm{g})$ were subjected to Western blotting on a denaturating $10 \%$ SDS-PAGE. Membranes were sequentially probed with antibodies to indicated signaling intermediates. Antibodies to phospho-Akt ${ }^{\mathrm{Ser} 473}$, Akt, phosphoERK $^{\text {Thr202/Tyr204, ERK, phospho-FAK }}{ }^{\mathrm{Tyr} 925}$, FAK, phosphop70S6K c-Myc, Her2, EGFR, phospho-cMET ${ }^{\text {Tyr1234/1235, cMET }}$ and phospho-IGF-1R $\mathrm{R}^{\text {Tyr1131 }}$ were purchased from Cell Signaling Technologies (Beverly, Mass., USA), and antibodies to $\beta$-actin and IGF-IR $\beta$ from Santa Cruz Biotechnologies (Santa Cruz, Calif., USA). For assessment of growth factor-induced activation of signaling pathways, cells were incubated with AUY922 (10 nM) for $24 \mathrm{~h}$ and subsequently stimulated for $15 \mathrm{~min}$ with HGF (50 ng/ml), EGF (40 ng/ml) and IGF-I (100 ng/ml).

\section{RNA Extraction and Real-Time RT-PCR}

RNA extraction and cDNA synthesis were performed as previously described [24]. Fresh isolated islet cells or cultured BON1 cells were homogenized and lysed with $600 \mu \mathrm{l}$ buffer RLT, and whole RNA was extracted using the RNeasy kit (Qiagen, Hilden, Germany) with on-column DNA digestion following the standard protocol provided by the manufacturer. The mRNA was reverse transcribed into cDNA with oligo-dT primers using the $\mathrm{Su}$ perscript 1st Strand System for RT-PCR (Invitrogen) at $42^{\circ} \mathrm{C}$ for $50 \mathrm{~min}$. All PCRs were carried out on a 7500 Real-Time PCR System (Applied Biosystems, Foster City, Calif., USA) over 40 cycles, with denaturation for $15 \mathrm{~s}$ at $95^{\circ} \mathrm{C}$ and combined annealing/extension at $60^{\circ} \mathrm{C}$ for $1 \mathrm{~min}$. Following an activation step at $95^{\circ} \mathrm{C}$ for $10 \mathrm{~min}$, determination of mRNA expression was performed over 40 cycles with $15 \mathrm{~s}$ of denaturation at $95^{\circ} \mathrm{C}$ and annealing/extension/data acquisition at $60^{\circ} \mathrm{C}$ for $60 \mathrm{~s}$ using the Power SYBR ${ }^{\circledR}$ Green PCR kit (Applied Biosystems). Primer sequences are available on request. Relative fold mRNA expression levels were determined using the $2\left({ }^{-\Delta \Delta} \mathrm{Ct}\right)$ method [25] with large ribosomal protein P0 (RPLP0) as housekeeping gene. All reactions were done in triplicate, and results are presented as means and standard errors.

\section{Statistical Analysis}

Survival curves were computed using the Kaplan-Meier method. The log-rank test was applied to identify significant differences. Differences in the mean of two samples were analyzed by an unpaired $t$ test. $p$ values $<0.05$ were considered statistically significant. Data were analyzed using SPSS software (version 16; SPSS Inc., Chicago, Ill., USA).

\section{Results}

\section{HSP90 Blockade in BON-1 Cells}

The pancreatic carcinoid cell line BON-1 was used for in vitro studies. In MTT assays, AUY922 led to a dosedependent inhibition of tumor growth. In particular, significant effects on growth were found after $48 \mathrm{~h}$ of treatment with $10 \mathrm{nM}$, whereas $5 \mathrm{nM}$ had only minor effects (data not shown). Next, we assessed the effects of HSP90 blockade on signaling pathways. After $24 \mathrm{~h}$, a dose-dependent inhibition of Akt and ERK phosphorylation was observed, which was paralleled by downregulation of total Akt and FAK expression. Moreover, AUY922 led to impairment of c-Myc expression, starting from $5 \mathrm{nM}$ AUY922. Surprisingly, no effect on HIF-1a expression was found (fig. 3a). Furthermore, no effects on constitu- 

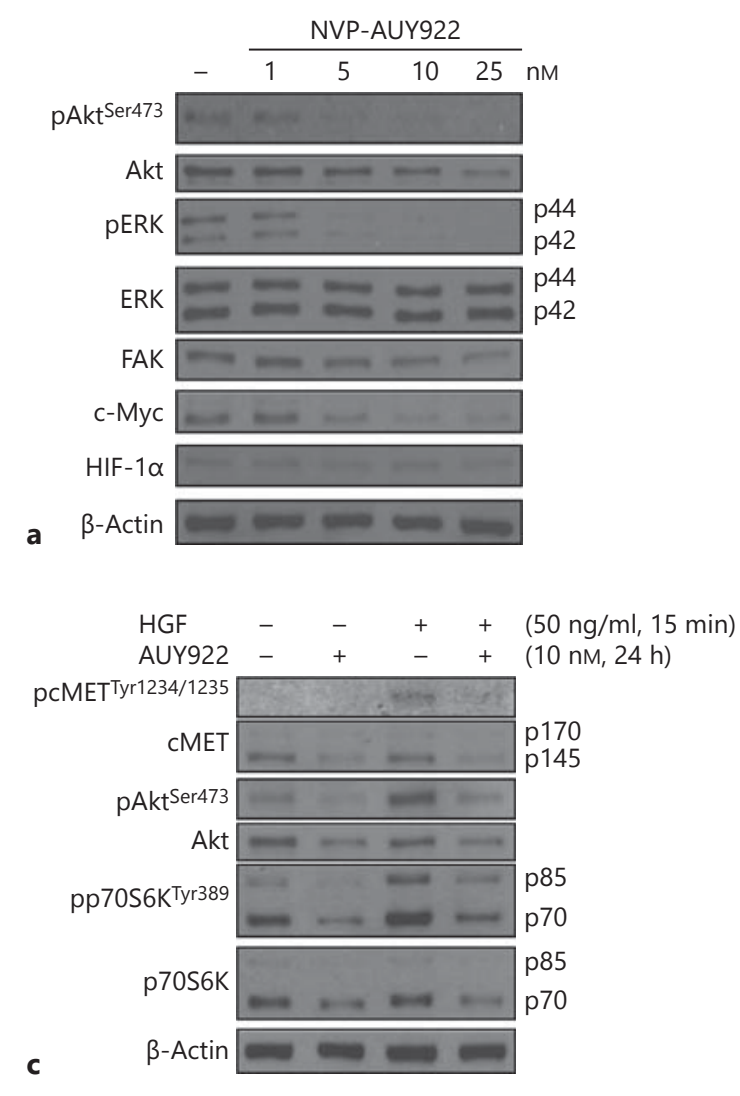

Fig. 3. a Incubation of BON-1 cells with HSP90 inhibitor AUY922 led to dose-dependent impairment of constitutive Akt and ERK phosphorylation. Expression of c-Myc was also reduced. b HSP90 blockade abrogated expression of Her2 and EGFR. Furthermore, EGF-induced Akt phosphorylation was diminished. c Similar,

tive expression or phosphorylation of Akt, ERK, FAK, cMyc and HIF- $1 \alpha$ were detectable after $2 \mathrm{~h}$ of treatment with the HSP90 blocker (data not shown).

\section{Impairment of Growth Factor-Induced Activation of} Akt/mTOR Pathway by HSP90 Inhibition

Since growth factor-induced activation of Akt/mTOR signaling is an important issue for tumor growth in pNENs, we subsequently assessed the effects of HSP90 inhibition on EGF-, HGF- and IGF-I-induced activation of this pathway in BON-1 cells [12]. Regarding EGF signaling, results showed a strong inhibition of Her2 and EGFR expression. Furthermore, EGF-induced Akt activation was impaired (fig. 3b). In HGF-stimulated BON-1 cells, targeting HSP90 diminished cMET phosphorylation in addition to inhibition of HGF-induced Akt and p70S6K
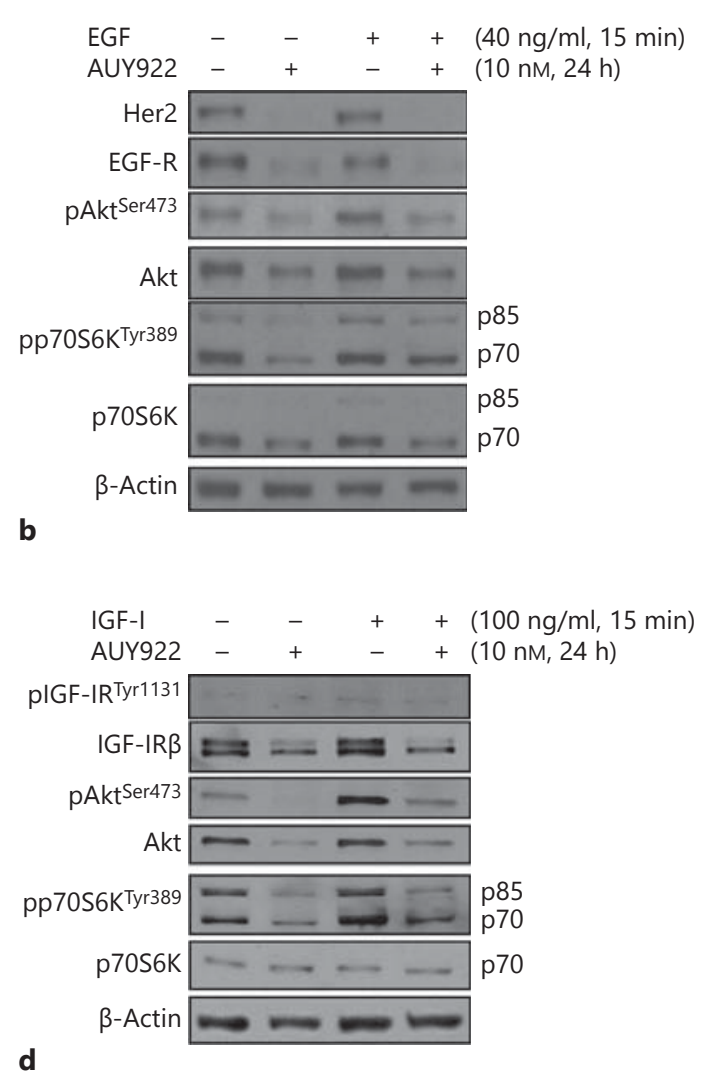

cMET expression and its phosphorylation upon HGF stimulation was impaired upon HSP90 inhibition. AUY922 also decreased HGF-induced Akt and p70S6k phosphorylation. d Targeting HSP90 impaired IGF-I-induced phosphorylation of Akt/p70S6K phosphorylation as well as total IGF-IR expression in BON-1 cells.

phosphorylation. Moreover, the corresponding cMET receptor was downregulated (fig. 3c). Finally, HSP90 blockade diminished expression of IGF-IR and impaired IGFI-induced phosphorylation of Akt and p70S6K (fig. 3d). In summary, these results implicate that treatment with the HSP90 inhibitor AUY922 impairs constitutive and growth factor-induced activation of oncogenic signaling cascades, in particular Akt/mTOR signaling, in human pancreatic endocrine cancer cell line BON-1.

\section{Development of Islet Cell Neoplasms in RIP1-Tag2 \\ Mice}

As previously described [20], we observed development of islet cell hyperplasia and subsequent islet cell tumors in RIP1-Tag2 mice compared to wild-type control mice. 


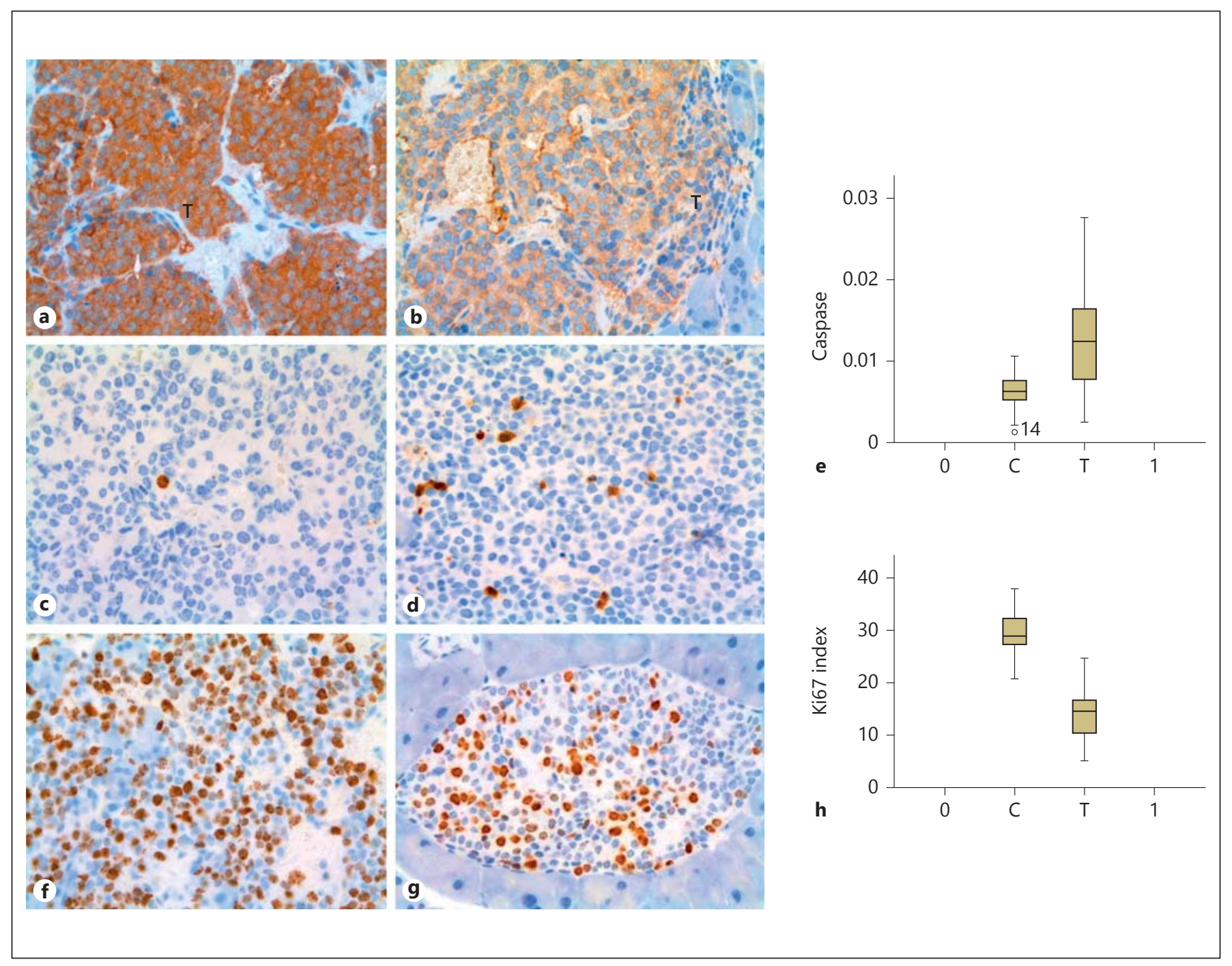

Fig. 4. a Islet tumor of an untreated RIP1-Tag2 mouse showed a strong positive staining for HSP90 in the tumor (T). b After treatment with AUY922, virtually all expression of HSP90 is lost in the tumor (T). a, b Magnification, $\times 40$. Caspase 3 staining without treatment (c) and upon HSP90 inhibition (d). e Significantly more $(p=0.000)$ caspase 3 -positive cells were found upon treat- ment (T) with AUY922 compared to control (C). Ki67 expression in the control group (f) and after treatment with AUY922 (g). h Statistically significant $(\mathrm{p}=0.000)$ reduction of tumor cell proliferation in vivo was found upon treatment (T) with AUY922 compared to control (C).

\section{HSP90 in Islet Cell Neoplasms of RIP1-Tag2}

Transgenic Mice

To determine target expression in RIP1-Tag2 islet cell neoplasms, the pancreata were harvested and stained for HSP90 using immunohistochemistry. As illustrated, islet tumor cells of untreated RIP1-Tag2 mice showed strong positive staining for HSP90 (fig. 4a). In contrast, only weak staining of HSP90 was detected in RIP1-Tag2 mice treated with AUY922 (fig. 4b). These observations demonstrate that HSP90 is expressed in islet cell neoplasms of
RIP1-Tag2 mice, and treatment with an HSP90 inhibitor reduces its expression, therefore providing a valid target for AUY922.

\section{AUY922 Augments Apoptosis in Islet Cell Tumors in vivo}

Treatment with AUY922 significantly augmented apoptosis in tumor cells, indicated by caspase-3 positivity. In the control group, only $0.6 \%$ of the tumor cells showed immunoreactivity for caspase-3 $(\mathrm{p}=0.02$; 

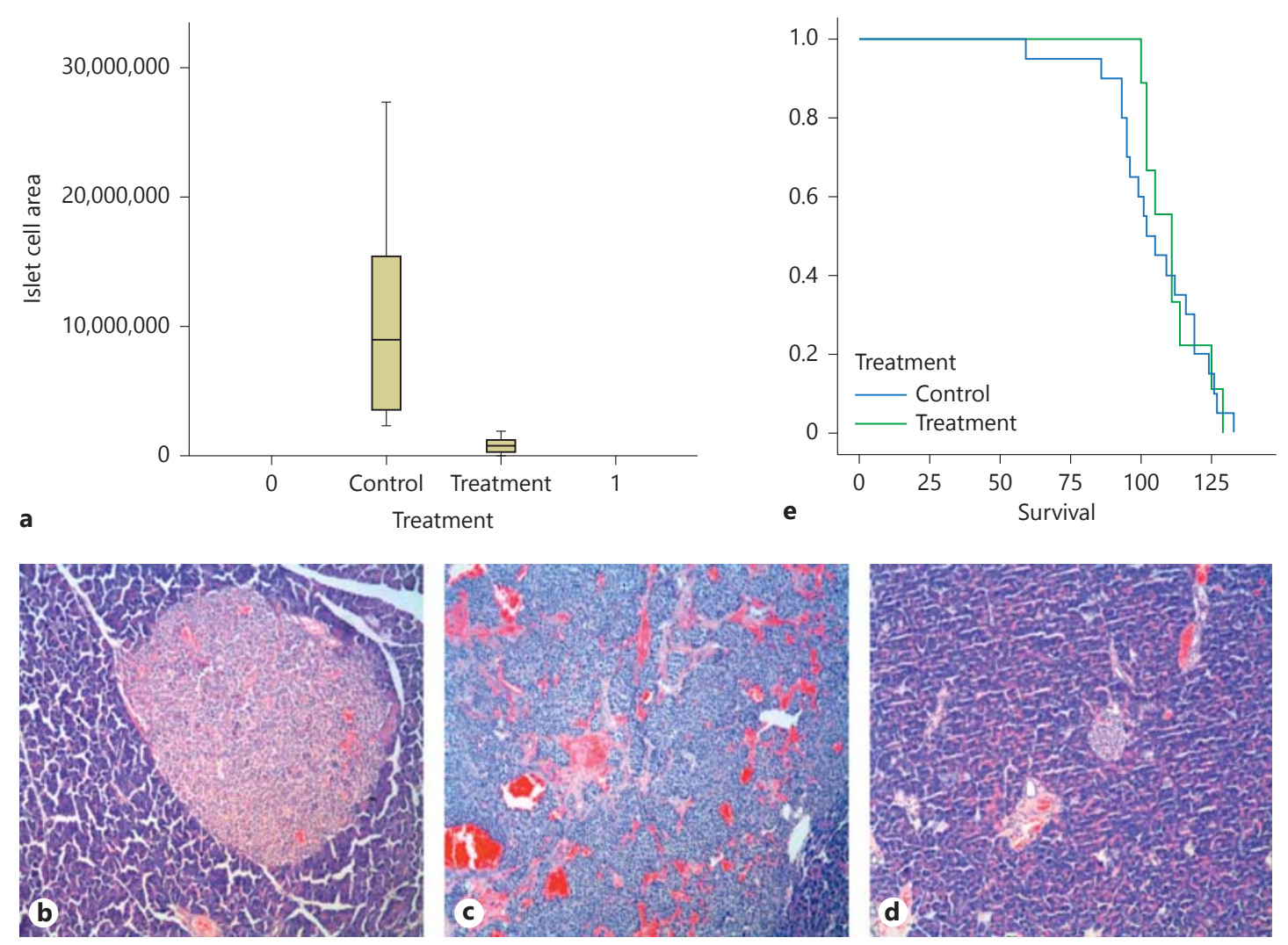

Fig. 5. a In the treated mice, AUY922 significantly reduced the tumor volume by $92 \%(p=0.000)$. Box plots showing mean tumor volume in $\mu \mathrm{m}$. b In treated mice, most islet cell tumors show only signs of hyperplasia, whereas in the untreated control mice, huge invasive islet cell carcinomas were detected (c). $\mathbf{d}$ Normal islet in a wild-type mouse. e HSP90 prolongs survival in AUY922-treated RIP1-Tag2 mice by 9 days $(\mathrm{p}=0.075)$. fig. 4c, e), whereas in RIP1-Tag2 mice treated with AUY922, 1.3\% of all counted tumor cells were caspase-3 positive (fig. $4 \mathrm{~d}, \mathrm{e})$.

\section{AUY922 Decreases Proliferation in Islet Cell Tumors in vivo}

Islet tumor cells were found to be highly proliferative. Accordingly, Ki67 expression was observed in 30\% of islet tumor cells in untreated RIP1-Tag2 mice (fig. 4f). In RIP1Tag2 mice treated with AUY922, a proliferation rate of only $14 \%$ was found, resulting in a significant $(46 \%)$ reduction upon HSP90 inhibition (fig. 4g, h; $\mathrm{p}=0.02$ ).

\section{AUY922 Decreases Tumor Growth}

Treatment of the RIP1-Tag2 mice began at 5 weeks of age, when every mouse had a few small but highly vascularized solid neoplasms, and was continued until week 12 when mice had end-stage disease. In treated animals,
AUY922 significantly reduced the tumor volume by $92.4 \%\left(786,258\right.$ vs. $\left.10,465.974 \mu \mathrm{m}^{2}, \mathrm{p}=0.000\right)$ compared to control mice (fig. 5a). In mice treated with AUY922, most of the islet cell neoplasms showed only signs of hyperplasia (fig. 5b), whereas in untreated RIP1-Tag2 mice, invasive islet cell neoplasms were detected (fig. 5c).

\section{AUY922 Prolongs Survival in RIP1-Tag2 Mice}

HSP90 inhibition by AUY922 prolonged overall median survival of RIP1-Tag2 mice by 9 days as compared to mock-treated animals (median survival 119 vs. 100 days). However, this failed to reach statistical significance $(\mathrm{p}=0.075$; fig. $5 \mathrm{e})$.

\section{Treatment of RIP1-Tag2 Mice with AUY922}

Diminishes Endogenous Insulin mRNA Expression

To determine whether blockade of HSP90 by AUY 922 affects adult pancreas and $\beta$-cell function in vivo, we per- 

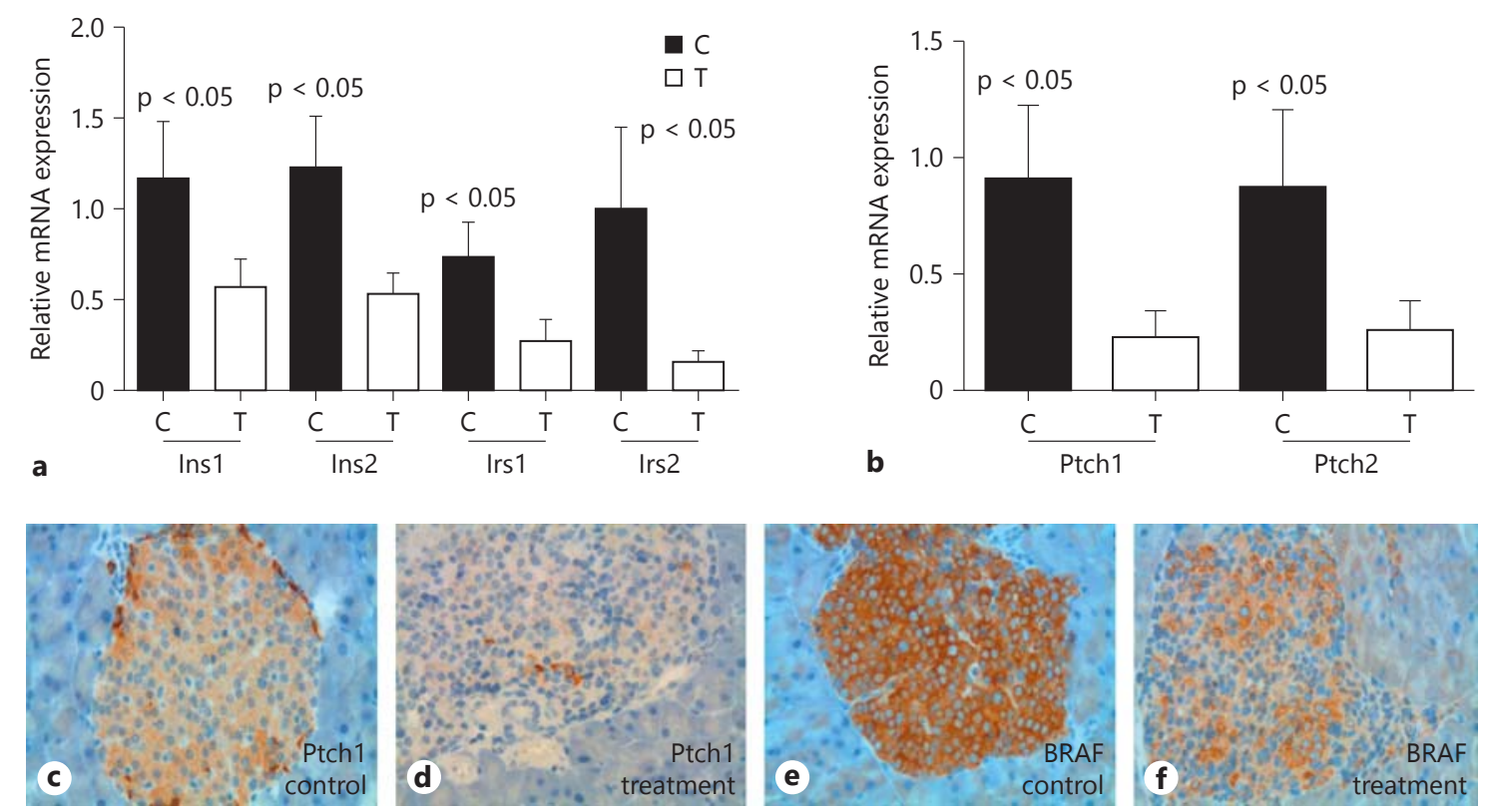

Fig. 6. Analysis of mRNA expression in purified islet cells derived from control and AUY922-treated RIP1-Tag2 mice $(n=4$ in each group). Data indicate mean $\pm \mathrm{SD}$. All C/T comparisons are statistically significant. a Insulin-related genes. Ins1, $-2=$ Insulin 1 and 2; Irs1, -2 = insulin receptor substrate 1 and 2. b Hedgehog target

formed quantitative real-time PCR for treated and untreated RIP1-Tag2 mice. Treatment with AUY922 led to significant reduction of endogenous insulin mRNA expression in islet cell neoplasms (fig. 6a).

\section{Downregulation of BRAF and Ptch1 in Islet Cell \\ Neoplasms by AUY922}

We have previously shown the importance of Ptch1 and Ptch2 - crucial parts of hedgehog signaling - in development of pNENs [20]. Therefore, expression of these factors was determined and quantitative real-time PCR for Ptch1 and Ptch2 demonstrated significant downregulation in the islet cell neoplasms of RIP1-Tag2 mice treated with AUY922 ( $\mathrm{p}<0.05$; fig. 6b). Immunostaining also confirmed a loss of Ptch1 upon HSP90 blockade (fig. 6c, d). These results suggest that not only HSP90 clients are affected by AUY922 but also other factors implicated in PNET progression.

Given the clinical and histopathological evidence that AUY922 impairs tumor growth, we finally explored BRAF as an HSP90 client protein in the neoplastic tissue of treated RIP1-Tag2 mice. Results from im- genes. Ptch1, $-2=$ Patched 1 and 2. c, $\mathbf{d}$ Islet tumor of an untreated RIP1-Tag2 mouse showed a strong positive staining for Ptch1 and BRAF in the islet cell neoplasms. e, $\mathbf{f}$ After treatment with AUY922, the tumor cells lost most of the expression of Ptch1 and BRAF. c-f Magnification, $\times 40$.

munohistochemistry revealed a loss of BRAF expression in islet cell neoplasms of treated RIP1-Tag2 mice (fig. 6e, f). This result shows that we achieved effective pharmacologic levels for HSP90 inhibition with AUY922 in vivo.

\section{Discussion}

Complete surgical resection is the most promising treatment for pNENs, but only a minority of patients are suitable for surgery due to advanced tumor stages [26]. Therefore, novel therapeutic options based on the molecular biology of this tumor are urgently needed. HSP90 has been considered a promising new therapeutic target in other neoplasms, including pancreatic ductal adenocarcinoma [27], hepatocellular carcinoma [28], breast cancer [29], esophageal and gastric cancers [30], and others. With regard to pNENs, HSP90 expression has been described in almost $95 \%$ of pNENs and, therefore, might be an interesting novel target for antineoplastic therapy in pNENs [6]. The present study provides evidence that 
targeting HSP90 impairs activation of oncogenic signaling including $\mathrm{Akt} / \mathrm{mTOR}$ activation. This is in line with our previous reports showing an impairment of Akt and Erk signaling in various other cancer entities such as pancreatic cancer, gastric cancer and hepatocellular carcinoma [13-15]. Moreover, the observation that HSP90 blockade impairs mTOR phosphorylation is of particular importance since the Akt/mTOR pathway has been implicated in tumorigenesis and progression in pNENs [12]. In addition, clinical studies with the mTOR inhibitor everolimus showed an improvement of progressionfree survival and, therefore, everolimus has been approved by the FDA for treatment of progressive or metastatic pNENs [31, 32]. Based on our results, one might speculate that the use of HSP90 inhibitors provides an advantage compared to the use of an mTOR inhibitor alone by targeting HSP90 clients in addition to the mTOR pathway.

The RIP1-Tag2 transgenic mouse model serves as a general prototype of the pathways, parameters, and molecular mechanisms of multistage tumorigenesis [18]. Lopez and Hanahan [19] have used the RIP1-Tag2 model to examine the utility of inhibitors of angiogenesis and matrix metalloproteinases. Recently, our group was the first to describe the dramatic effect of hedgehog inhibition by i.p. injections of cyclopamine and LDE225, two well-described Smoothened inhibitors [20]. To our knowledge, this is the first report demonstrating a role of HSP90 in an autochthonous islet cell tumor mouse model. After treatment for several weeks, no invasive carcinoma was found in histopathological evaluation. Downregulation of BRAF was found in the tumor cells of AUY 922 treated mice, and survival was prolonged in the AUY 922 treated RIP1-Tag2 mice for 9 days. To this day, more than 200 HSP90 client proteins have been discovered. The aforementioned serin/threonine-protein kinase BRAF is such a client of HSP90 and mutated in approximately $7 \%$ of all human malignancies [33]. Sobczak et al. [34] could show that BRAF plays an essential role in the regulation of neoangiogenesis - a crucial step towards invasive carcinomas in RIP1-Tag2 mice. Our recent works went a step further. By inhibiting BRAF with sorafenib we could prolong survival and reduce tumor volume in treated RIP1-Tag2 mice [35]. In the present study using the HSP90 inhibitor AUY922, we found similar positive effects in treated mice. Therefore, targeting the expression of BRAF through the inhibition of HSP90 and in that manner disrupting crucial pathways involved in tumor development further supports the new therapeutic approach in pNENs.
Some of our earlier studies suggested the significance of the Hedgehog pathway in the development of islet cell neoplasms in RIP1-Tag2 mice. In order to pick up where our recent work left off, we now evaluated whether the inhibition of HSP90 would show similar findings. Indeed, we found a downregulation of Ptch1 - an integral part of this signaling cascade - in immunostaining as well as in quantitative real-time PCR in mice treated with AUY922. The fact that Ptch1 has not yet been described as an HSP90 client protein suggests either the wide-ranging abilities of HSP90 inhibitors to disrupt tumor signaling cascades or the need for further investigation of HSP90 and its client proteins. Either way, our data indicate that combining AUY922 with a specific inhibitor of the Hedgehog pathway could lead to an even stronger suppression of tumor growth.

Furthermore, our data showed a significant downregulation of insulin-mRNA in mice treated with AUY922 compared with mice in the control group. It is a question of future studies to answer whether the treatment with AUY 922 is capable of reducing the symptoms of hypoglycemia that are mostly responsible for the loss of life quality in patients with advanced malignant insulinoma. But on the other hand, the mere possibility of an induced diabetes mellitus using AUY922 in other tumor settings should also be taken into consideration.

The present results provide the first evidence that targeting HSP90 with AUY 922 may be a very attractive target for patients with pNENs by disrupting multiple signaling cascades. After achieving a tumor volume reduction by $92 \%$, we feel that this observed effect is meaningful given the strong underlying 'genetic force' and the extremely rapid course of disease. The observations of this present study have obvious clinical implications, and it is our hope that this potent pharmacological HSP90 inhibitor will soon be evaluated in a clinical setting since this will be the only way to ultimately learn whether or not this approach has therapeutic potential in human disease.

\section{Acknowledgements}

V.F. was supported by a Research Grant of the University Medical Center Gießen and Marburg. S.A.L. was supported by a Research Grant of the German Research Council (LA 1988/3-1).

\section{Disclosure Statement}

We declare that there is no conflict of interest that could be perceived as prejudicing the impartiality of the research reported. 


\section{References}

$>_{1}$ Öberg K, Eriksson B: Endocrine tumors of the pancreas. Best Pract Res Clin Gastroenterol 2005; 19:753-781.

-2 Fendrich V, Langer P, Celik I, Bartsch DK, Zielke A, Ramaswamy A, Rothmund M: An aggressive surgical approach leads to longterm survival in patients with pancreatic endocrine tumors. Ann Surg 2006;244:845-851; discussion 852-853.

3 Metz DC, Jensen RT: Gastrointestinal neuroendocrine tumors: pancreatic endocrine tumors. Gastroenterology 2008;135:1469-1492.

4 Plockinger U, Wiedenmann B: Biotherapy. Best Pract Res Clin Endocrinol Metab 2007; 21:145-162.

5 Eriksson B: New drugs in neuroendocrine tumors: rising of new therapeutic philosophies? Curr Opin Oncol 2010;22:381-386.

-6 Mayer P, Harjung A, Breinig M, Fischer L, Ehemann V, Malz M, Scherübl H, Britsch S, Werner J, Kern MA, et al: Expression and therapeutic relevance of heat-shock protein 90 in pancreatic endocrine tumors. Endocr Relat Cancer 2012;19:217-232.

7 Trepel J, Mollapour M, Giaccone G, Neckers L: Targeting the dynamic HSP90 complex in cancer. Nat Rev Cancer 2010;10:537-549.

8 Whitesell L, Lindquist SL: HSP90 and the chaperoning of cancer. Nat Rev Cancer 2005; 5:761-772.

-9 Gilbert JA, Adhikari LJ, Lloyd RV, Halfdanarson TR, Muders MH, Ames MM: Molecular markers for novel therapeutic strategies in pancreatic endocrine tumors. Pancreas 2013; 42:411-421.

10 Hansel DE, Rahman A, House M, Ashfaq R, Berg K, Yeo CJ, Maitra A: Met proto-oncogene and insulin-like growth factor binding protein 3 overexpression correlates with metastatic ability in well-differentiated pancreatic endocrine neoplasms. Clin Cancer Res 2004 10:6152-6158.

11 Hennessy BT, Smith DL, Ram PT, Lu Y, Mills GB: Exploiting the PI3K/AKT pathway for cancer drug discovery. Nat Rev Drug Discov 2005;4:988-1004.

12 Missiaglia E, Dalai I, Barbi S, Beghelli S, Falconi M, della Peruta M, Piemonti L, Capurso G, Di Florio A, delle Fave G, et al: Pancreatic endocrine tumors: expression profiling evidences a role for AKT-mTOR pathway. J Clin Oncol 2010;28:245-255.

13 Lang SA, Klein D, Moser C, Gaumann A, Glockzin G, Dahlke MH, Dietmaier W, Bolder U, Schlitt HJ, Geissler EK, et al: Inhibition of heat shock protein 90 impairs epidermal growth factor-mediated signaling in gastric cancer cells and reduces tumor growth and vascularization in vivo. Mol Cancer Ther 2007;6:1123-1132.
14 Lang SA, Moser C, Fichnter-Feigl S, Schachtschneider P, Hellerbrand C, Schmitz V, Schlitt HJ, Geissler EK, Stoeltzing O: Targeting heat-shock protein 90 improves efficacy of rapamycin in a model of hepatocellular carcinoma in mice. Hepatology 2009;49:523-532.

15 Moser C, Lang SA, Hackl C, Wagner C, Scheiffert E, Schlitt HJ, Geissler EK, Stoeltzing O: Targeting HSP90 by the novel inhibitor NVPAUY922 reduces growth and angiogenesis of pancreatic cancer. Anticancer Res 2012;32: 2551-2561.

16 Sessa C, Shapiro GI, Bhalla KN, Britten C, Jacks KS, Mita M, Papadimitrakopoulou V, Pluard T, Samuel TA, Akimov M, et al: Firstin-human phase I dose-escalation study of the HSP90 inhibitor AUY922 in patients with advanced solid tumors. Clin Cancer Res 2013; 19:3671-3680.

17 Eccles SA, Massey A, Raynaud FI, Sharp SY, Box G, Valenti M, Patterson L, de Haven Brandon A, Gowan S, Boxall F, et al: NVPAUY922: a novel heat shock protein 90 inhibitor active against xenograft tumor growth, angiogenesis, and metastasis. Cancer Res 2008;68:2850-2860.

18 Hanahan D: Heritable formation of pancreatic beta-cell tumours in transgenic mice expressing recombinant insulin/simian virus 40 oncogene. Nature 1985;315:115-122.

19 Lopez T, Hanahan D: Elevated levels of IGF-1 receptor convey invasive and metastatic capability in a mouse model of pancreatic islet tumorigenesis. Cancer Cell 2002;1:339-353.

20 Fendrich V, Rehm J, Maschuw K, Waldmann J, Bucholz M, Christofori G, Slater EP, Bartsch DK: Hedgehog inhibition with cyclopamine represses tumor growth and prolongs survival in a transgenic mouse model of islet cell tumors. Ann Surg 2011;254:818-823.

21 Gaspar N, Sharp SY, Eccles SA, Gowan S, Popov S, Jones C, Pearson A, Vassal G, Workman P: Mechanistic evaluation of the novel HSP90 inhibitor NVP-AUY922 in adult and pediatric glioblastoma. Mol Cancer Ther 2010;9:1219-1233.

22 Fendrich V, Esni F, Garay MV, Feldmann G, Habbe N, Jensen JN, Dor Y, Stoffers D, Jensen J, Leach SD, et al: Hedgehog signaling regulates facultative progenitor activity in regenerating exocrine pancreas. Gastroenterology 2008;135:621-631.

23 Parekh D, Ishizuka J, Townsend CM Jr, Haber B, Beauchamp RD, Karp G, Kim SW, Rajaraman S, Greeley G Jr, Thompson JC: Characterization of a human pancreatic carcinoid in vitro: morphology, amine and peptide storage, and secretion. Pancreas 1994;9:83-90.

24 Feldmann G, Fendrich V, McGovern K, Bedja D, Bisht S, Alvarez H, Koorstra JB, Habbe N, Karikari C, Mullendore M, et al: An orally bioavailable small-molecule inhibitor of Hedgehog signaling inhibits tumor initiation and metastasis in pancreatic cancer. Mol Cancer Ther 2008;7:2725-2735.
25 Livak KJ, Schmittgen TD: Analysis of relative gene expression data using real-time quantitative PCR and the 2(-delta delta C(T)) method. Methods 2001;25:402-408.

-26 Halfdanarson TR, Rabe KG, Rubin J, Petersen GM: Pancreatic neuroendocrine tumor (PNETs): incidence, prognosis and recent trend toward improved survival. Ann Oncol 2008;19:1727-1733.

27 Song D, Chaerkady R, Tan AC, García-García E, Nalli A, Suárez-Gauthier A, López-Ríos F, Zhang XF, Solomon A, Tong J, Read M, et al: Antitumor activity and molecular effects of the novel heat shock protein 90 inhibitor, IPI504 , in pancreatic cancer. Mol Cancer Ther 2008;7:3275-3284.

28 Breinig M, Caldas-Lopes E, Goeppert B, Malz M, Rieker R, Bergmann F, Schirmacher P, Mayer M, Chiosis G, Kern MA: Targeting heat shock protein 90 with non-quinone inhibitors: a novel chemotherapeutic approach in human hepatocellular carcinoma. Hepatology 2009;50:102-112.

29 Baselga J: Treatment of HER2-overexpressing breast cancer. Ann Oncol 2010;21:36-40.

30 Lee W, Patel JH, Lockhart AC: Novel targets in esophageal and gastric cancer: beyond antiangiogenesis. Expert Opin Investig Drugs 2009;18:1351-1364.

31 Yao JC, Shah MH, Ito T, Bohas CL, Wolin EM, Van Cutsem E, Hobday TJ, Okusaka T, Capdevila J, de Vries EG, et al: Everolimus for advanced pancreatic neuroendocrine tumors. N Engl J Med 2011;364:514-523.

32 Pavel ME, Hainsworth JD, Baudin E, Peeters M, Hörsch D, Winkler RE, Klimovsky J, Lebwohl D, Jehl V, Wolin EM, et al: Everolimus plus octreotide long-acting repeatable for the treatment of advanced neuroendocrine tumours associated with carcinoid syndrome (RADIANT-2): a randomised, placebo-controlled, phase 3 study. Lancet 2011;378:20052012.

33 da Rocha Dias S, Friedlos F, Light Y, Springer C, Workman P, Marais R: Activated B-RAF is an Hsp90 client protein that is targeted by the anticancer drug 17-allylamino-17-demethoxygeldanamycin. Cancer Res 2005;65:1068610691.

-34 Sobczak I, Galabova-Kovacs G, Sadzak I, Kren A, Christofori G, Baccarini M: B-Raf is required for ERK activation and tumor progression in a mouse model of pancreatic beta-cell carcinogenesis. Oncogene 2008;27:4779-4787.

- 35 Fendrich V, Maschuw K, Rehm J, Buchholz M, Holler JP, Slater EP, Bartsch DK, Waldmann J: Sorafenib inhibits tumor growth and improves survival in a transgenic mouse model of pancreatic islet cell tumors. Sci World J 2012;52:9-15. 